\title{
Indoor environmental quality of the Valli Theatre: outcomes on sound, light and thermo- hygrometry
}

\author{
Antonella Bevilacqua ${ }^{1,{ }^{*}, \text { Sara Francesca Gelati }}{ }^{2, \dagger}$, and Francesca Merli ${ }^{3, \dagger}$ \\ ${ }^{1}$ Department of Industrial Engineering, University of Parma, Area delle Scienze, Parma, Italy \\ ${ }^{2}$ Department of Architecture, University of Bologna, Italy \\ ${ }^{3}$ CIRI -Interdepartmental Centre for Industrial Research in Building and Construction, University of \\ Bologna, Italy
}

\begin{abstract}
The characteristics of a performing arts space have a great influence on the experience that both artists and audiences have during a show. Therefore, it is of great importance to understand the sound field behaviour, the lighting, and the thermo-hygrometry of the ambient conditions existing inside this cultural heritage. The aim of this paper is the presentation of a complete assessment in relation to the comfort of an Opera theatre on its whole. As such, it has been undertaken a study in relation to the acoustic listening situations other than to the parameters related to the light level and temperature comfort of the Valli Theatre of Reggio Emilia. The acoustic characterization has been undertaken in line with the ISO 3382 standard measurements procedure by capturing the room impulse response (RIR), while the light intensity has been studied by using the lux meter. In addition, the thermo-hygrometer has been used to photograph the comfort related to temperature and relative humidity inside the main hall.
\end{abstract}

\section{Introduction}

The attention of the researchers to the cultural heritage should be of paramount importance if the intention of the study is to highlight its value and importance, to be protected for the new generations. Previous studies on the Valli theatre of Reggio Emilia have already been undertaken by scholars, mainly focusing on one of the many aspects related to environmental comfort. This paper deals with the data representation by covering the entire comfort of an Opera theatre, a place that for the complexity and variety of the artistic shows should be intensely investigated.

Several measurements have been undertaken inside the Valli theatre, in particular by detecting the acoustics, the lighting, and the thermo-hygrometric conditions of the main hall. The availability of different equipment allowed the authors to be assessing different

\footnotetext{
*antonella.bevilacqua@unipr.it

†sarafrancesca.gelati@studio.unibo.it

†rancesca.merli8@unibo.it
} 
aspects of the ambient and therefore to call attention to a few background features that require to be optimized. The outcomes herein introduced are intended to embed the whole comfort of such a historical building.

\section{Research Background}

Several previous investigations [1-20] occurred in the last decades are found to be mainly focused on the room response to the sound waves inside the theatre, hence, only on the acoustic aspect.

In particular, some studies regard the acoustic integrity of several theatres, including the Valli theatre to be preserved for the occasion of restoration works occurred in the second half of the $20^{\text {th }}$ century. In this case, acoustic measurements were undertaken before and after the refurbishment works with relative benefits and detriments.

Other research studies took place in other spaces, including the Valli theatre, and regard the acoustic measurements that came through innovative equipment, with relative discussions on monoaural and binaural acoustic parameters [21-24].

\section{Historical Background}

During the night between $21^{\text {st }}$ and $22^{\text {nd }}$ of April 1851, a fire destroyed the Cittadella theatre, a building born in 1741 in the area where the Ariosto theatre stands actually. When such architecture dedicated to the artistic performance became lost, the citizens organized themselves in finding an alternative structure where the shows could continue, but none of the existing buildings was suitable for that purpose [25-30]. As such, Mayor Ghirardini wrote a letter to the Municipal Council asking about the reconstruction of the fired building to be undertaken as a priority. The architect chosen to design the project of a new theatre was Cesare Costa, who suggested an alternative place where the new theatre should be erected because the reconstruction of the old one would be expensive, not in line with the safety regulations and uncomfortable for the narrow volume [31-36].

The works started in 1852 but the necessity of more funding brought to the idea of selling the boxes, that had been bought by aristocrats and nobles, other than professionals belonging to the middle class [4]. Many of the buildings adjacent to the project site were demolished in order to obtain materials useful for the erection of the new construction [3740].

For this theatre, the lighting system supplied by gas (not composed of candles, instead) was considered an innovation for that time [1-2].

The architectonic decorations of the audience area and the proscenium arch were realized by Girolamo Magnani, who had a similar experience in the Regio Theatre of Parma. The theatre opened officially in 1857 and was called Comunicativo [2-3]. The management of the artists and the shows was taken by private companies until 1957 when the City Council decided to acquire all the cultural activity of the town. Ballets and operas were alternatively promoted by the new administration and accepted by the citizens [2].

For the occasion of the death of a popular actor, the City Council decided to dedicate the theatre to Romolo Valli, which has been the official name of the theatre since 1980 [3].

\section{Architectural Organization}

The Valli theatre has a total capacity of 1122 seats distributed as 414 in the stalls and 520 on the elevated boxes. The stalls are separated by perpendicular corridors running along the main axes and coronated by four orders of balconies, surmounted by a gallery 
having a capacity of further 180 seats occasionally occupied. The royal box is located at the centre of the second and third order. The ceiling of the main hall is composed of eight medallions painted by Domenico Pellizzi, which represent the glory of the Italian theatre (e.g. melodrama, tragedy, comedy, etc.) [4]. Fig. 1 shows the interior design of the main hall.

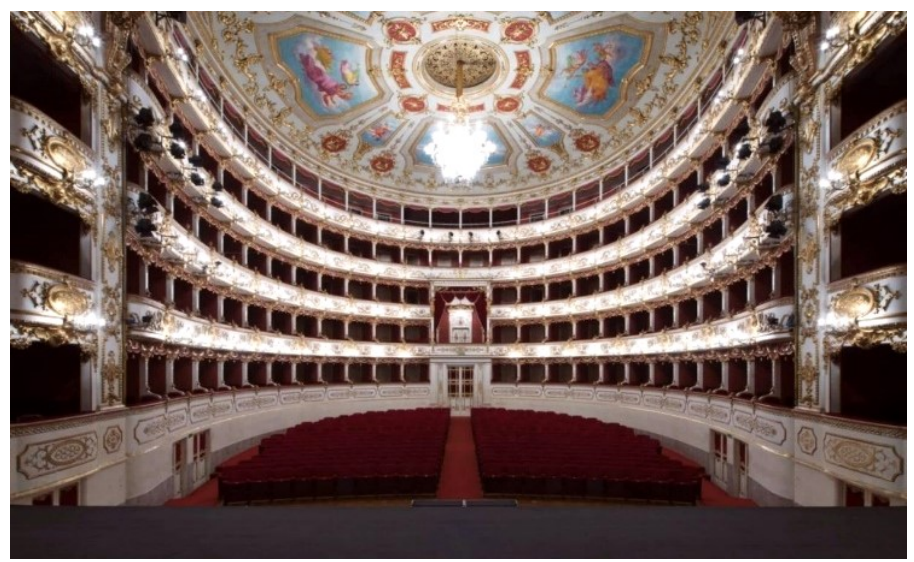

Fig. 1. View of the main hall of the Valli theatre of Reggio Emilia

Flourishing decorations are installed all around the main hall; in particular, there is a chandelier composed of 72 crystals, being $3.75 \mathrm{~m}$ high and having a diameter of $3.05 \mathrm{~m}$.

The stage has dimensions of $20.5 \times 31.2 \mathrm{~m}[\mathrm{~L} \times \mathrm{W}]$ and the proscenium arch $14 \mathrm{~m}$ large and $22.5 \mathrm{~m}$ high. The wooden planks of the stage are inclined of $5 \%$, against the $2 \%$ of the stalls floor. The orchestra pit is $2.09 \mathrm{~m}$ high and $5.9 \mathrm{~m}$ deep, with $2.07 \mathrm{~m}$ of its depth located below the stage floor, as shown in Fig. 2.

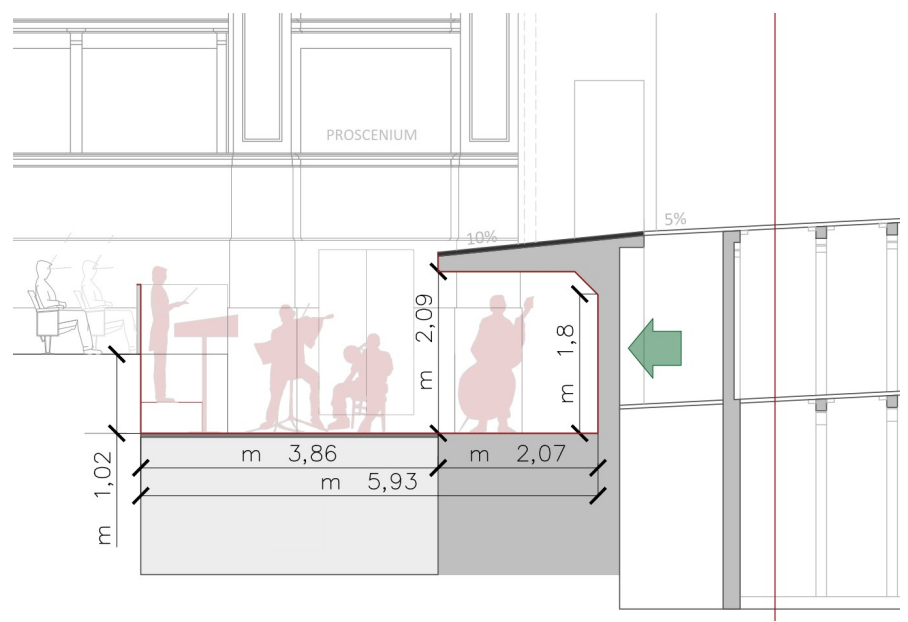

Fig. 2. Transversal section of the orchestra pit of the Valli theatre.

The Valli theatre has a horseshoe shape plan layout, as visible in Fig. 3, where the geometry of the performance space and the audience area is herein indicated. 


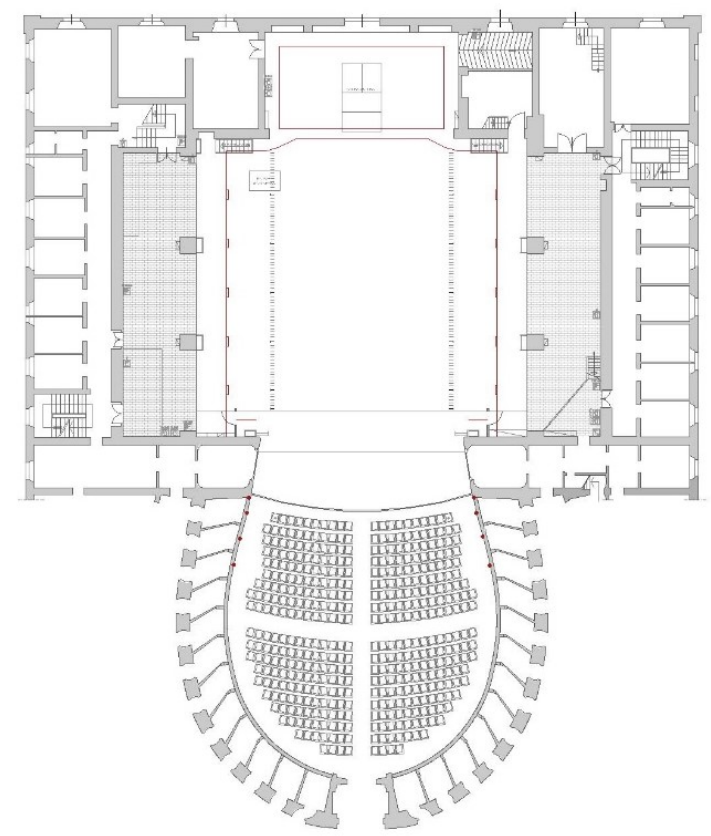

Fig. 3. Plan layout of the Valli theatre of Reggio Emilia

Table 1 summarizes the architectural features of the Valli theatre.

Table 1. Architectural characteristics of the Valli theatre of Reggio Emilia

\begin{tabular}{|c|c|}
\hline Description & Features \\
\hline Type of plan layout & Horseshoe box \\
\hline Total volume $\left(\mathrm{m}^{3}\right)$ & 31480 \\
\hline Total capacity (no. of seats) & 1122 \\
\hline Stage dimension $(\mathrm{m})[\mathrm{L} \times \mathrm{W}]$ & $20.5 \times 31.2$ \\
\hline Inclination of stage floor $(\%)$ & $5 \%$ \\
\hline Inclination of stalls area $(\%)$ & $2 \%$ \\
\hline
\end{tabular}

\section{Measurements}

\subsection{Acoustic survey}

An acoustic survey was undertaken inside the theatre to understand the behaviour of the existing volume under acoustic perspective through the objective parameters obtained in line with the standard requirements outlined in ISO 3382-1 [40-43]. The acoustic survey was carried out with the following equipment:

- Equalised omnidirectional loudspeaker (Look Line);

- Microphones:

○ Binaural dummy head (Neumann KU-100); 
- B-Format (Sennheiser Ambeo);

○ Omnidirectional microphone (Bruel\&Kjaer).

The sound source was placed at $1.4 \mathrm{~m}$ from the finished floor, while the receivers were installed at the height of $1.2 \mathrm{~m}$ on stalls and boxes. The excitation signal emitted by the sound source was the Exponential Sine Sweep (ESS) [40-44] having a duration of $15 \mathrm{~s}$ in a uniform sound pressure level for the range between $40 \mathrm{~Hz}$ and $20 \mathrm{kHz}$. Fig. 4 shows the measurement positions of sound source and receivers across the sitting areas.

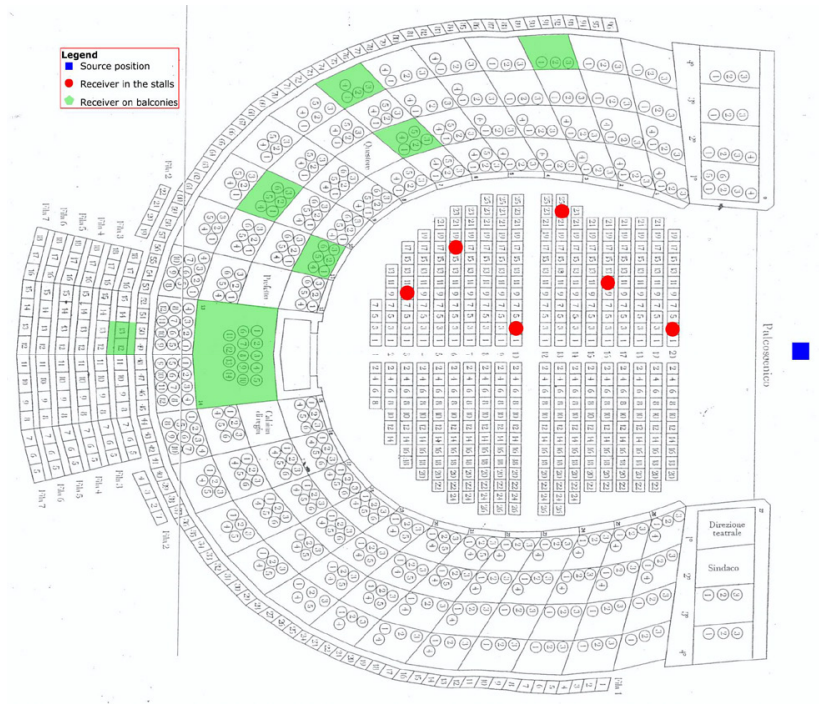

Fig. 4. Scheme of the acoustic equipment location during the measurements in the Valli theatre of Reggio Emilia.

The measurements were undertaken in unoccupied conditions and without any scenery nor acoustic chamber mounted. It would be worthy if measurements with the audience could take place but given the Covid-19 restrictions still ongoing at different levels it was not possible to arrange a survey with the presence of spectators. The sound absorption data with the presence of an audience differs from empty seats [40-46] and hence would give a more accurate estimation of reverberation times as a function of frequency [45-47].

\subsection{Lighting}

On the same occasion, a lighting survey was undertaken inside the theatre to assess the light level applied to this volume in line with the standard requirements stated by EN124641 [48]. The lighting survey was carried out with the following equipment:

- Lux meter (Hanna HI-97500).

All the characteristics of the lux meter are summarised in Table 2.

Table 2. Technical characteristics of the Lux meter (Hanna HI-97500).

\begin{tabular}{|c|lc|}
\hline Feature & \multicolumn{2}{|c|}{ Values } \\
\hline Scale & klux & $0.01-19.99$ \\
\hline
\end{tabular}




\begin{tabular}{|c|lc|}
\hline Feature & \multicolumn{2}{|c|}{ Values } \\
\hline Resolution & klux & 0.01 \\
\hline Precision & By reading $\pm 6 \%$ \\
\hline
\end{tabular}

The equipment has been installed at $1.4 \mathrm{~m}$ from the finished floor in different positions across the stalls area. All the lights of the main hall were on at the time of measurements. Fig. 5 shows the position of the lux meter and the thermo-hygrometric meter.

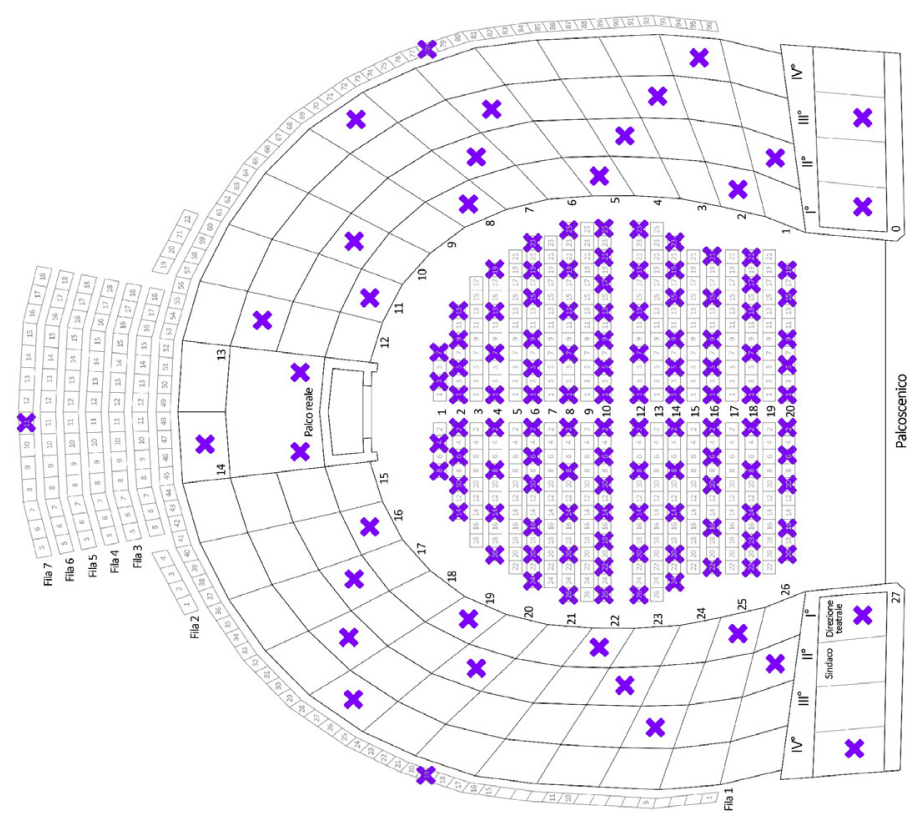

Fig. 5. Scheme of the lighting and thermo-hygrometric equipment location during the measurements in the Valli theatre of Reggio Emilia.

\subsection{Temperature Measurements}

The thermo-hygrometric conditions of the Valli theatre of Reggio Emilia have been measured in accordance with the ISO 13370 [50]. The equipment employed was the following:

- Thermo Hygrometric meter (Hanna HI-93640).

The calibration of the equipment has been undertaken at $20^{\circ} \mathrm{C}$ and $60 \%$; all the characteristics of the thermo-hygrometric meter are summarised in Table 3.

Table 3. Technical characteristics of the Thermo Hygrometric meter (Hanna HI-93640).

\begin{tabular}{|c|c|}
\hline Feature & \multicolumn{2}{|c|}{ Values } \\
\hline Scale & R.H. $\quad 5.0-95.0 \%$ \\
\hline
\end{tabular}




\begin{tabular}{|l|ll|}
\hline Feature & \multicolumn{2}{|c|}{ Values } \\
\hline \multirow{4}{*}{ Resolution } & ${ }^{\circ} \mathrm{C}$ & $0.0-60.0$ \\
\cline { 2 - 3 } & ${ }^{\circ} \mathrm{F}$ & $32.0-140.0$ \\
\hline \multirow{4}{*}{ Precision } & R.H. & $0.1 \%$ \\
\cline { 2 - 3 } & ${ }^{\circ} \mathrm{C}$ & 0.1 \\
\cline { 2 - 3 } & ${ }^{\circ} \mathrm{F}$ & 1 \\
\hline \multirow{4}{*}{} & R.H. & $\pm 5 \%$ \\
\cline { 2 - 3 } & ${ }^{\circ} \mathrm{C}$ & \pm 0.4 \\
\cline { 2 - 3 } & ${ }^{\circ} \mathrm{F}$ & \pm 1 \\
\hline
\end{tabular}

The equipment has been installed at $1.4 \mathrm{~m}$ from the finished floor in different positions across the stalls area. The measurements were undertaken on the $3^{\text {rd }}$ of May inside the main hall, with the mechanical ventilation system switched off $[6,37,39]$.

\section{Results}

\subsection{Acoustic Outcomes}

Several acoustic parameters defined in the international standards ISO 3382-1, such as the early decay time (EDT), reverberation time $\left(\mathrm{T}_{20}\right)$, clarity indexes $\left(\mathrm{C}_{50}, \mathrm{C}_{80}\right)$ and definition $\left(D_{50}\right)$ have been analysed. Fig. 6 to Fig. 9 show the comparison between the values by performing the impulse response measurements inside the Valli theatre.

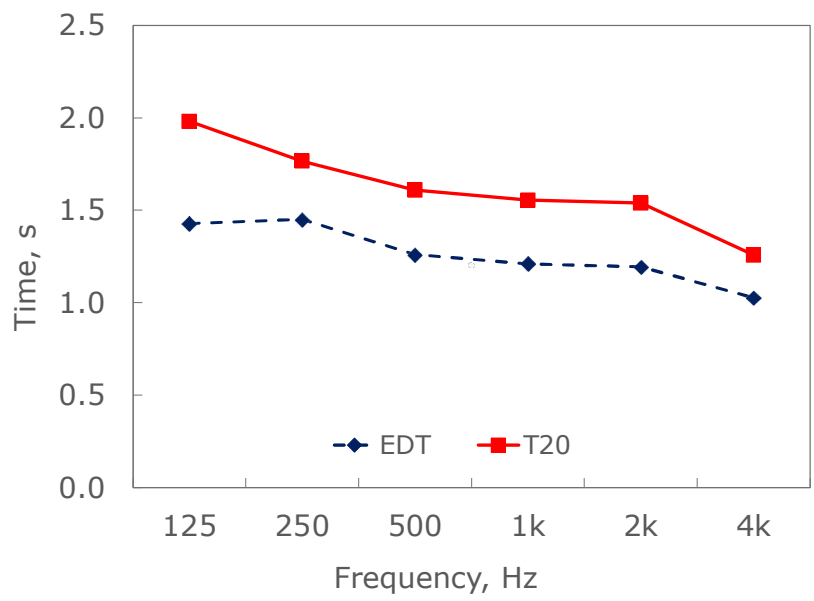

Fig. 6. Measured results of Early Decay Time (EDT) and Reverberation Time $\left(\mathrm{T}_{20}\right)$.

Fig. 6 shows the frequency response of the EDT and $\mathrm{T}_{20}$ parameters. If it is considered that the optimal values of EDT range between $1.8 \mathrm{~s}$ and $2.6 \mathrm{~s}$, as defined by Jordan and 
others [14-18], this target has not been achieved by the measured values related to the selected bandwidth.

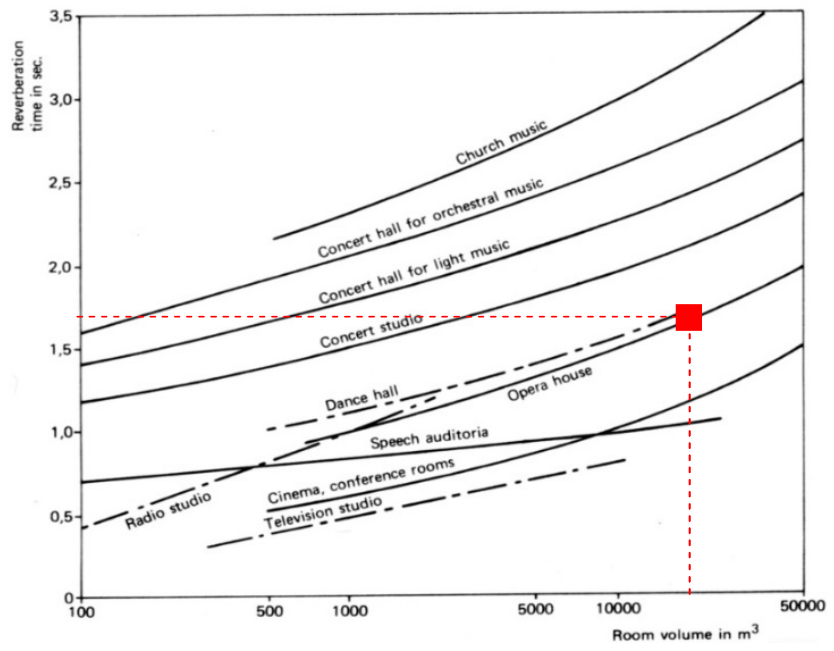

Fig. 7. Optimal reverberation time values in function of room volume

In terms of reverberation time $\left(\mathrm{T}_{20}\right)$ the averaged value of all the frequency bands results within the target assigned to an Opera house of such volume size [11-13; 39, 40, 43], as shown in Fig. 7, even though it is within the lower limit. This means that the Valli theatre has a good response for both speech and music performance.

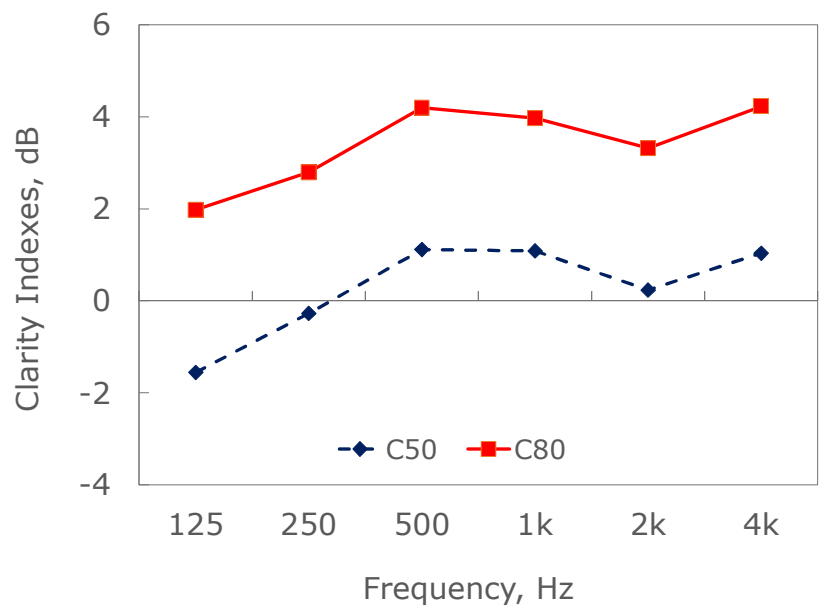

Fig. 8. Measured results of clarity indexes $\left(\mathrm{C}_{50}\right.$ and $\left.\mathrm{C}_{80}\right)$.

Following the research studies by Reichardt and others [11-13, 41], the optimal values for speech clarity index $\left(\mathrm{C}_{50}\right)$ would be $\geq 3 \mathrm{~dB}$. In the Valli theatre, this parameter floats between -2 and $+2 \mathrm{~dB}$ at low and high-frequency bands, respectively, as shown in Fig. 8 . However, this shortfall slightly below the lowest range limit is not to be intended as a negative result. In this case, the listening perception of speech finds a balance between the sound energy arriving within the $50 \mathrm{~ms}$ and the reflections coming after $50 \mathrm{~ms}$.

In terms of music $\left(\mathrm{C}_{80}\right)$, the optimal values should be comprised between -2 and $+2 \mathrm{~dB}$, according to Jordan [40]. This target has been achieved only at $125 \mathrm{~Hz}$, where the value is equal to $+2 \mathrm{~dB}$, while the values related to the other frequency bands are up to $2 \mathrm{~dB}$ higher 
than this latest one. Translated in other words, this outcome means that the music would be very clear, especially at high frequencies.

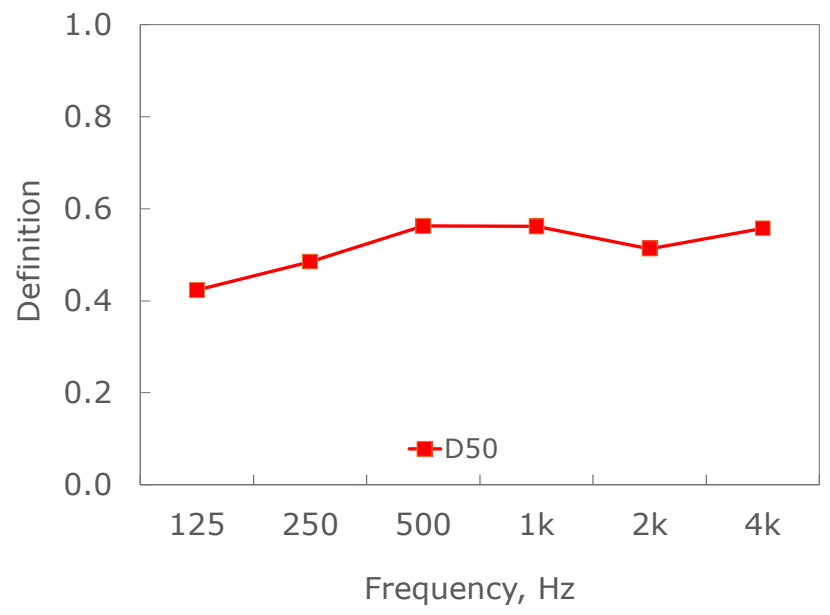

Fig. 9. Measured results of Definition $\left(D_{50}\right)$.

A good speech definition is achieved for values higher than 0.5 (i.e. $50 \%$ ), while the optimal values for music definition are lower than 0.5 (i.e. 50\%) [40]. On this basis, the results obtained in the Valli theatre, as shown in Fig. 9, are found to be around 0.5, meaning that the listening conditions are suitable for both speech and music.

\subsection{Lighting Results}

The lighting data have been elaborated with the Surfer software, where the input data of the lux scenario were necessary to create a coloured map as indicated in Fig. 10. The input data consisted of the plan layout of the room, the coordinates of the points where the measurements were undertaken, and the values obtained for each selected position [48]. The colour scale ranges between blue, indicating a low level of light, and clear/white shades, indicating high levels of light.

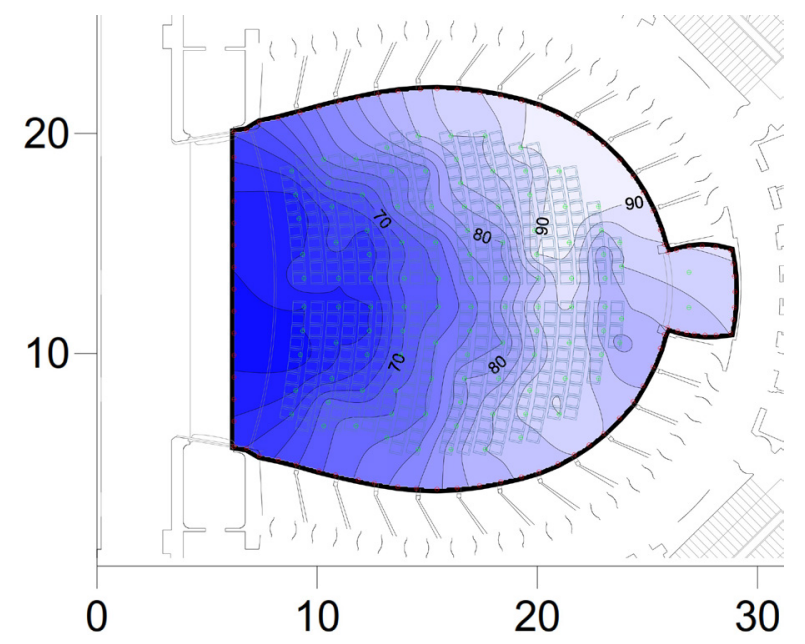

Fig. 10. Lighting levels maps obtained for the Valli theatre of Reggio Emilia 
The results shown in Fig. 10 are comprised of between 62 and 90 lux. These values are found to be below the lower range limit indicated by EN12464-1 [48], which outlines a lighting range between 150 lux and 250 lux for theatres and concert halls [48]. However, based on experience on a similar room type, the lighting levels inside the Valli theatre are found to be higher than any other historical Opera house [49].

This outcome should be considered in function of the candlelight approach, which aims to reproduce the existing atmosphere when the theatre was just open [3-4].

Rather than focusing on the absolute values, the authors consider furthermore the unbalance lighting conditions across the main hall. Fig. 10 shows a difference of 30 lux between the back seats of the hall and the area in proximity of the stage. This lack of uniformity is perceivable by the users, even if the theatre had both the main hall and stage equipped with lights on $[3,4,48]$.

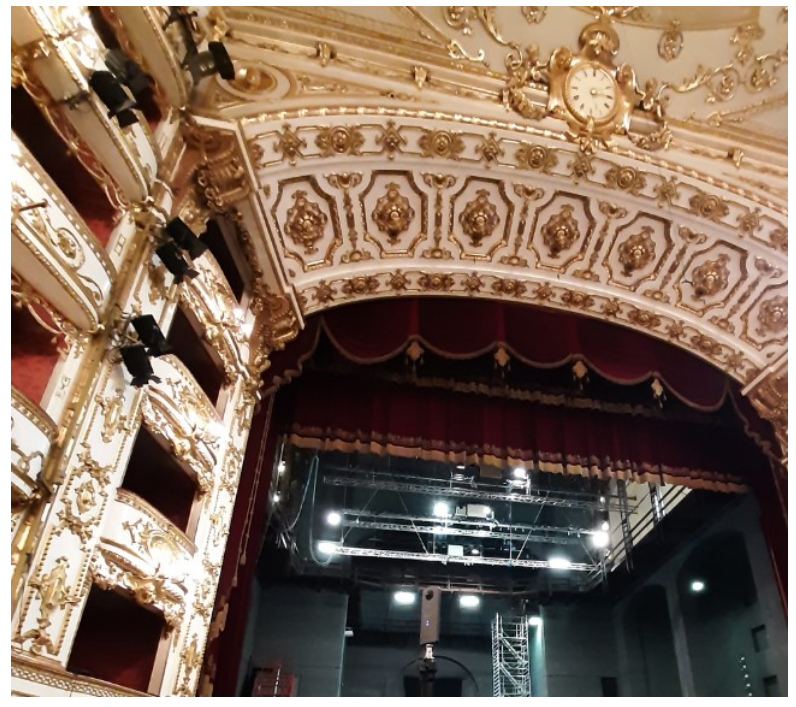

Fig. 11. Lighting difference between the stage and the stalls area.

Fig. 11 shows the difference in terms of lighting between the stage and the sitting area. The directionality of the light beams of the stage has been planned to do not glare at the audience, but to be highlighting the actors moving onto the stage, only.

\subsection{Hygrothermal Conditions}

In accordance with the target set by regulations, the temperature range varies between $22^{\circ} \mathrm{C}$ and $24^{\circ} \mathrm{C}$, which is within the optimal range [50]. The low values have been found in two points of the stalls area, while the warmer zone is in the back of the hall, including the main entrance. Fig. 12 shows the temperature variance across the stalls area having a colour range comprised between orange shades, meaning a high temperature, and clear/white tint that stands for low temperature. 


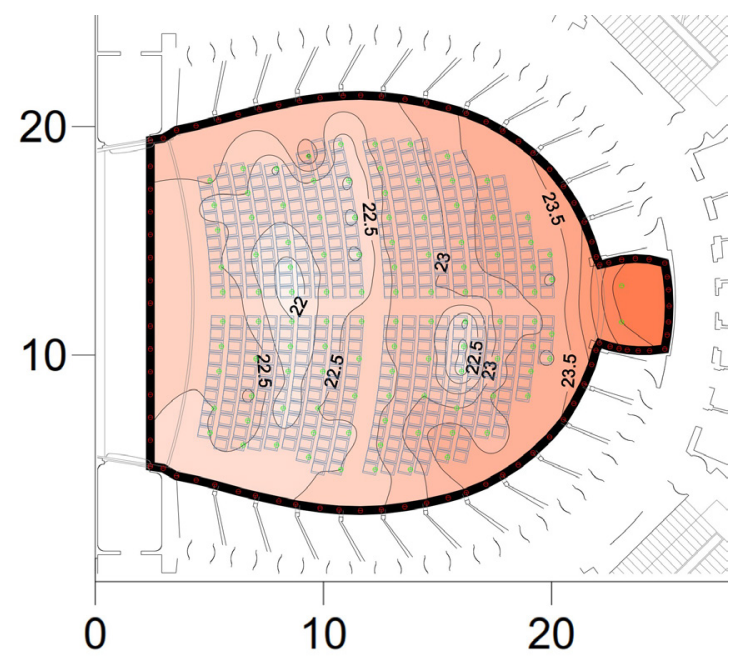

Fig. 12. Temperature variance inside the Valli theatre of Reggio Emilia.

Although related to $2^{\circ} \mathrm{C}$, the lack of uniformity should not be existing inside a room volume of such size. This outcome can create the effect of a slight discomfort of the users by sitting for all the duration of the artistic performance [11-13, 21-24].

In terms of relative humidity, Fig. 13 indicates the values based on the colour scale, going from blue (low relative humidity) and clear/white tinge.

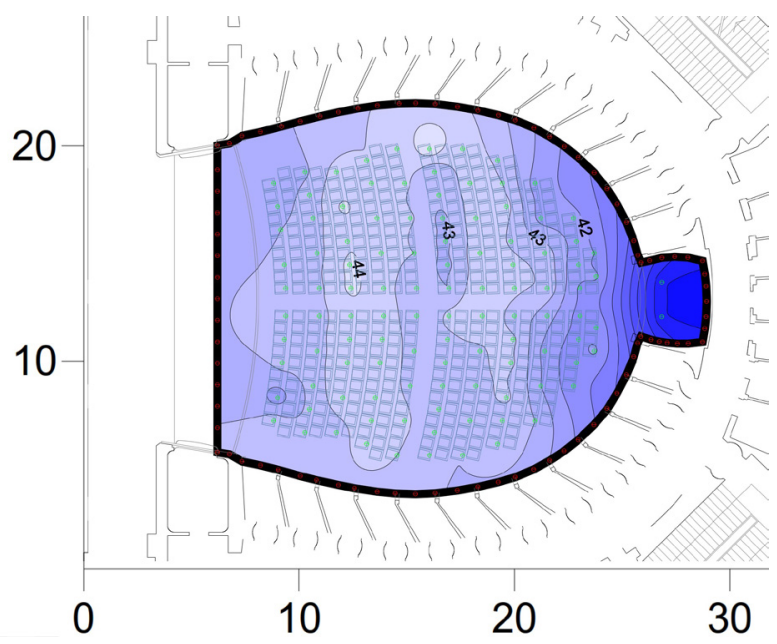

Fig. 13. Relative humidity variance inside the Valli theatre of Reggio Emilia.

Fig. 13 shows the values measured inside the Valli theatre. In particular, the range varies between $38 \%$ and $44 \%$, to be pretty steady across the sitting area and considerably lower at the entrance. This zone distinction is created by the concentration of the relative humidity in this corner of the hall.

\section{Conclusions}

Theatres and concert halls belong to a specific building type that sometimes is not perfectly designed given the compromise between the historical characteristics of the structure and the current needs as required by regulations. The intention of this paper is to 
highlight the strengths and the weaknesses of the perception that users and artists can be impacted by spending several hours inside theatres. In particular, this paper deals with the technical study of the Valli theatre of Reggio Emilia, which has been assessed under acoustic, lighting, and thermal conditions. The outcomes of the results say that the overall acoustic of the Valli theatre is suitable for both prose and musical shows, even if the music performance could be clearer than what it should be, based on literature investigations.

In terms of lighting levels, all the values result below the lower range limit outlined by the standard. Although many of the Opera theatres have similar results because of evoking the candlelight experience as they were intentionally designed by the architects, the difference of 30 lux between the first and the last rows of seats across the stalls is significant. A more homogeneous spread of lighting conditions would be more comfortable. However, the design of the stage lights, to be not affecting the audience, is the right approach for performing arts space. Some considerations on the balance between the two objectives could be revised.

The thermal hygrometry of the existing conditions inside the theatre is found to be within the optimal values set by regulations. However, the difference of $2^{\circ} \mathrm{C}$ localized in two points of the stalls areas could rise a slight discomfort of the listeners that are to be assisting the live performance for more than one hour.

A better outcome has been found in relation to the relative humidity, which is more uniform across the seats except for the entrance, where a concentration of low values unbalances the even conditions. However, the measurements have been undertaken without any mechanical ventilation in operation.

Future studies will be covering further acoustic tests with the presence of spectators, at different percentages of occupancy, while in terms of thermo-hygrometry additional surveys will be undertaken in different seasons of the year, in order to compare and evaluate any changes between the outcomes of this paper and future results.

\section{References}

1. D. Seragnoli, Il Mulino Ed. (1987).

2. S. Davoli, M. De Michelis, O. Lanzarini, Silvana Ed. (2007).

3. G. Crocioni, Forni Ed. (1979).

4. A. Farina, L. Tronchin, Acustica 86, 737-745 (2000).

5. L. Tronchin, M. Manfren, B. Nastasi, Renewable \& sustainable energy reviews 95, 341-353 (2018).

6. L. Tronchin, K. Fabbri, Energies 10(10), 1621 (2017).

7. A. Farina, L. Tronchin, Acustica 86, 737-745 (2000).

8. L. Tronchin, V.L. Coli, VL. AES J Audio Eng Soc 63, 671-683 (2015).

9. A. Farina, L. Tronchin, Acta Acustica united with Acustica 99, 118-125 (2013).

10. L. Tronchin, D.J. Knight, International Journal of Historical Archaeology 20, 127-145 (2016).

11. L. Tronchin, F. Merli, M. Manfren, Applied Acoustics, 172, 107598 (2021)

12. L. Tronchin, F. Merli, M. Dolci, Applied Acoustics, 172, 107595 (2021)

13. R. Shimokura, L. Tronchin, A. Cocchi, Y. Soeta J. Sound Vib. 330(14), 3526-3537 (2011).

14. M. Tang, X. Zheng, Appl. Energy. 242, 1010-1021 (2019).

15. F. Lisi, G. Santi, F. Leccese, D. Testi, F. Cinelli, Acta Hortic. 1215, 81-88 (2018). 
16. C. Bibbiani, C. Gargari, C. A. Campiotti, G. Salvadori, F. Fantozzi, Innovative Biosystems Engineering for Sustainable Agriculture, Forestry and Food Production, Springer International Publishing, 169-177, (2020).

17. Y. He, H. Yu, A. Ozaki, N. Dong, S. Zheng, Energy Build. 148, 142-154 (2017).

18. A. Vila, G. Pérez, C. Solé, A.I. Fernández, L.F. Cabeza, Build. Environ. 48, 101-106 (2012).

19. M. Caniato, Applied Acoustics, 169107484 (2020)

20. J. Coma, G. Pérez, C. Solé, A. Castell, L.F. Cabeza, Renew. Energy. 85, 1106-1115 (2016).

21. D. Zirkelbach, S.R. Mehra, K.P. Sedlbauer, H.M. Künzel, B. Stöckl, Energy Build. 145, 79-91 (2017).

22. M.E. Ali, A. Alabdulkarem, Constr. Build. Mater. 138, 276-284 (2017).

23. A. Paiva, S. Pereira, A. Sá, D. Cruz, H. Varum, J. Pinto, Energy Build. 45, 274-279 (2012).

24. S. Charca, J. Noel, D. Andia, J. Flores, A. Guzman, C. Renteros, J. Tumialan, Energy Build. 108, 55-60 (2015).

25. K. Wei, C. Lv, M. Chen, X. Zhou, Z. Dai, D. Shen, Energy Build. 87, 116-122 (2015).

26. D.M. Nguyen, A.C. Grillet, T.M.H. Diep, C.N. Ha Thuc, M. Woloszyn, Constr. Build. Mater. 155, 852-866 (2017).

27. D.M. Nguyen, A.C. Grillet, Q.B. Bui, T.M.H. Diep, M. Woloszyn, Constr. Build. Mater. 186, 686-698 (2018).

28. Panyakaew, S. Fotios, Energy Build. 43, 1732-1739 (2011).

29. J. Hirunlabh, J. Khedari, S. Charoenvai, Build. Environ. 38, 435-441 (2003).

30. J. Khedari, N. Nankongnab, J. Hirunlabh, S. Teekasap, Build. Environ. 39, 59-65 (2004).

31. L. Tronchin, M.C. Tommasino, K. Fabbri, International Journal of Sustainable Energy Planning and Management 3, 49-62 (2014).

32. L. Tronchin, M. Manfren, L.C. Tagliabue, Sustainable Cities and Society 27, 296-306 (2016).

33. L. Tronchin, K. Fabbri, Energy Policy 48, 176-184 (2012).

34. B. Grassi, E.A. Piana, G.P. Beretta, M. Pilotelli, Energies 14(1), 25 (2021)

35. L. Tronchin, M. Manfren, P.A. James, Energy 165, 26-40 (2018).

36. U. Berardi, 1. Tronchin, M. Manfren, N. Nastasi, Energies 11 (4) 872 (2018)

37. L. Tronchin, K. Fabbri, C. Bertolli, Energies 11 (8) 2123 (2018)

38. J.S. Bradley, J. Acoust. Soc. Am. 99 (2) (1996).

39. L. Tronchin, Appl. Acoustic, 177-107933 (2021).

40. V.L. Jordan, Appl. Acoust. 14 (1981).

41. W. Reichardt, O. Abel Alim, W. Schmidt, Acta Acust. 3 (1975).

42. ISO 3382-1: Geneva, Switzerland (2009).

43. L. Tronchin, A.Bevilacqua, Applied Acoustics, 180, 108102 (2021)

44. M.Caniato C.Schmid A.Gasparella , Applied Acoustics, 166, 107339 (2020)

45. L. Grondhal, Nordic Theatre Studies, 26 (2) (2014). 
46. W.E. Gruber, Modern Dramatist: a casebook of major Br. Irish, and Am. Playwrights (2013).

47. S. Dustagheer, Moving Shakespeare Indoors: Perf. And Rep. in Jacobean Playhouse (2012).

48. EN ISO 12464-1: Geneva, Switzerland (2003)

49. J.M. Speigle, D.H. Brainard, J. of Optical Soc. of America: Optics and Image Science, and Vision, 13 (3) (1996).

50. ISO 13370: Geneva, Switzerland (2007) 